\title{
O Papel da Educação Digital na mudança de Paradigma na Arquitetura Contemporânea: da padronização à customização em massa
}

The Role of Digital Education in Paradigm Shifting in Contemporary Architecture: from standardization to mass customization

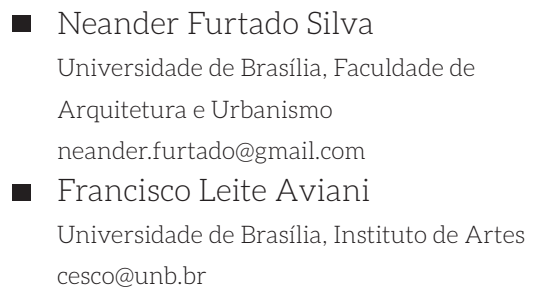

\begin{abstract}
Mass customization, which may lead to greater variety of architectural solutions, seems to be a concept mostly unknown and difficult to grasp or hard to believe by many. We argue in this paper that education may have a rule to play in bringing about a better understanding of these among students and professionals. We show here the results of a survey on people's beliefs about mass standardization and mass customization and a comparative study of students' design projects produced under a certain pedagogical strategy and how these might be influenced by their education.
\end{abstract}

Keywords: Architecture, Digital Fabrication, Mass Customization, Architectural Education Paradigm Shift

\section{Introdução}

A indústria da construção tem se baseado em componentes padronizados e produzidos em massa, como um paradigma central, principalmente desde o advento do movimento moderno na arquitetura (Polette et al, 1995, p. 45-49). A revolução industrial arraigou firmemente na percepção das pessoas a ideia de que, para produzir quaisquer coisas por custos acessíveis, é essencial que as mesmas sejam produzidas de forma serial, repetitiva. Qualquer coisa que se constitua em um artefato único é imediatamente identificada como necessariamente mais cara e menos acessível.

A customização em massa na indústria da construção segue um caminho diferente do descrito acima. Componentes construtivos são produzidos com fins específicos, para se tornarem partes singulares em contextos únicos de um edifício específico. As economias obtidas por meio da automação do processo de fabricação significam que os custos de produção de componentes singulares dificilmente serão maiores do que os custos de fabricação de componentes padronizados (Kolarevic, 2003, p. 31-53; Franken, 2003, p. 138; Kieran et al, 2004, p. 131-153; Schodek et al, 2005, p. 339-344; Kolarevic e Klinger, 2008, p. 18; Menges, 2008, p. 198; Barros, Duarte e Chaparro, 2011, p. 182; Benros et al, 2011, p. 248).

\section{Problemática}

A aplicação do conceito de customização em massa se encontra em estágio bem mais avançado em outras indústrias, como a aeroespacial, a automobilística e a naval (Kolarevic, 2003, p. 8-10). Esta longa utilização tem levado a um nível de variabilidade de seus produtos muito maior do que aquele observado até o momento na indústria da construção civil.

Muitos autores, incluindo os citados acima, têm argumentado que estamos testemunhando atualmente uma mudança de paradigma na história da arquitetura. Nesta mudança, argumenta-se que a customização em massa, conforme descrita em nossa introdução, está gradativamente tomando o lugar uma vez ocupado pela padronização em massa.

Contudo, o conceito de customização em massa parece ser desconhecido, pela maioria das pessoas, difícil de compreender ou ainda de se acreditar como algo viável por muitos. A lógica aparentemente simples da padronização em massa parece difícil de ser contraditada.

Disto resulta uma prática pedagógica e profissional avessa à diversidade e a uma maior riqueza de formas e soluções arquitetônicas.

"Forma sempre segue a função" (Sullivan, 1896, apud Higgins, 2009, p. 211) se tornou um dos principais corolários da arquitetura moderna. Moussavi (2009, p. 7) argumenta que Sullivan atribuía um significado significativamente mais abrangente ao termo 'função' do que a interpretação restritiva adotada pelos modernistas no início do século XX. Estes entendiam 'função' como a utilidade da forma construída.

Sob esta visão restritiva, pode-se logicamente inferir que 
a forma em arquitetura é alegadamente consequência natural de outra variável, a função. Portanto, em se sustentando a premissa, poder-se-ia dizer que não é importante pensar na forma, uma vez que esta é mera consequência de outra variável: a 'função' em sentido utilitarista. O resultado prático disto são programas de necessidade formulados sem nenhuma condicionante formal ou, em outras palavras, que especifiquem, a priori, linguagem ou requisitos definidores da forma. Apresentam-se, apenas, condicionantes 'funcionais', em sua interpretação utilitária, acrescidos no máximo dos condicionantes construtivos e ambientais. O resultado desta compreensão de 'função' e do conceito fortemente arraigado da padronização em massa é uma arquitetura repetitiva e pouco contextualizada.

Entretanto, este não é um pressuposto desta pesquisa. Se forma fosse sempre consequência da função, a cada função corresponderia apenas uma forma. Ora, isto não é verdade. Basta ressaltar que em um concurso público de projetos de arquitetura a função é uma só, mas os resultados formais aceitáveis são vários.

Nosso pressuposto aqui é de que a forma, enquanto ser belo, é por si só função (Niemeyer, 2005, p. 52-54; Mitchell, 2008, p. 39-49; Moussavi, 2009, p. 7). A forma é a primeira variável que chama a atenção de qualquer observador de uma arquitetura. Não há arquitetura sem forma. Não há cliente que não perceba certa linguagem como necessária, certos critérios de composição, ou que não tenha certas expectativas plásticas e estéticas.

O ensino de arquitetura desempenha, neste momento, um importante papel nesta morosidade de mudança de paradigma ao se apegar firmemente a interpretações restritivas de conceitos como o de Sullivan e ao conceito de padronização como pressupostos insuperáveis.

Estabelecemos, então, nossa problemática de pesquisa a partir das questões acima apresentadas. Em primeiro lugar, qual seria o papel desempenhado pelo ensino de arquitetura para a mudança de paradigma em favor da diversidade e da customização em massa?

Em segundolugar, este papel pode ser bem desempenhado por meio de uma introdução, predominantemente teórica, aos conceitos de fabricação digital e customização em massa? Ou seria mais bem desempenhado inicialmente por meio da inclusão de requisitos formais nos programas de necessidades das tarefas de projeto? Ou ainda, pode ser mais bem desempenhado por meio da exigência de se conceber o projeto através de representações digitais tridimensionais?

\section{Hipótese}

Mostraremos neste artigo que o conceito de padronização em massa ainda se encontra firmemente arraigado na mente da maioria das pessoas, particularmente arquitetos e estudantes de arquitetura.

Entretanto, mostraremos também, que o ensino de arquitetura poderia desempenhar, por meio de mais de uma estratégia pedagógica, um papel promissor na mudança deste paradigma.

Portanto, propusemos algumas hipóteses para serem testadas nesta pesquisa. A primeira delas supõe que a simples apresentação e ilustração do conceito de customização em massa seriam suficientes para convencer os alunos de que a padronização (esuas resultantes manifestações arquitetônicas) estaria sendo superada e que os mesmos passariam a projetar de uma forma mais livre em consequência disto.

A segunda hipótese é a de que os alunos produziriam formas não orgânicas ou curvilíneas muito mais em consequência da introdução de certas linguagens como requisito de projeto, do que propriamente como resultado de uma aceitação intelectual da viabilidade da customização em massa.

A terceira hipótese supõe que o estabelecimento da representação tridimensional digital como requisito inicial para a concepção de projetos de formas customizadas, ao invés de ter um efeito supostamente restritivo, na realidade tem efeito amplificador da adoção de soluções orgânicas ou curvilíneas apresentadas pelos alunos.

\section{Objetivo}

O objetivo principal desta pesquisa foi verificar até que ponto a experiência de sete anos e meio de integração de recursos digitais em uma disciplina de ateliê de projeto da Faculdade de Arquitetura e Urbanismo da Universidade de Brasília tem contribuído para que:

1. O conceito de customização em massa seja mais bem compreendido;

2. Uma maior diversidade de soluções de projeto e uma adoção mais frequente de formas orgânicas curvilíneas foram ou não apresentadas no período acima especificado e quais as principais razões disto.

\section{Método de Investigação}

O método adotado para a verificação das hipóteses acima apresentadas se baseou em duas linhas de investigação: em primeiro lugar foi elaborado um questionário com o objetivo de verificar o nível de compreensão e aceitação dos conceitos de fabricação digital e customização em massa entre profissionais de projeto e alunos de arquitetura.

Este questionário foi aplicado primeiro entre estudantes de pós-graduação (arquitetos e engenheiros) da escola anteriormente citada. Esta pesquisa foi realizada por meio da apresentação de imagens de artefatos produzidos serialmente em massa e artefatos produzidos por meio de customização em massa. Juntamente com estas imagens foi aplicado um questionário identificando a formação educacional e a experiência profissional do entrevistado.

O questionário foi em seguida aplicado a três grupos diferentes de alunos de ateliê de projeto de arquitetura da mesma escola supracitada. $O$ primeiro deles era composto por 
alunos do primeiro semestre do curso os quais não haviam ainda sido introduzidos aos meios digitais de projeto e nem tão pouco à customização em massa. O segundo grupo era composto por alunos do terceiro e quarto semestres, mas que tinham sido introduzidos aos meios digitais de projeto e ao conceito de customização em massa. O terceiro grupo também era composto por alunos do terceiro e quarto semestres, mas que haviam sido introduzidos somente aos meios digitais de projeto, sem, contudo, conhecerem o conceito de customização em massa.

Um conjunto de objetos de conhecimento comum foi utilizado de forma a facilitar a identificação dos mesmos ao invés de se utilizar artefatos arquitetônicos mais especializados. A principal razão disto foi proporcionar uma fácil compreensão por parte de alunos ainda no início do curso, em condições de igualdade em relação àqueles mais veteranos. Os dois grupos de objetos, ou seja, xícaras de chá, mostradas nas Figuras 1e 2, foram utilizadas como ilustrações que acompanhavam o questionário desta pesquisa.

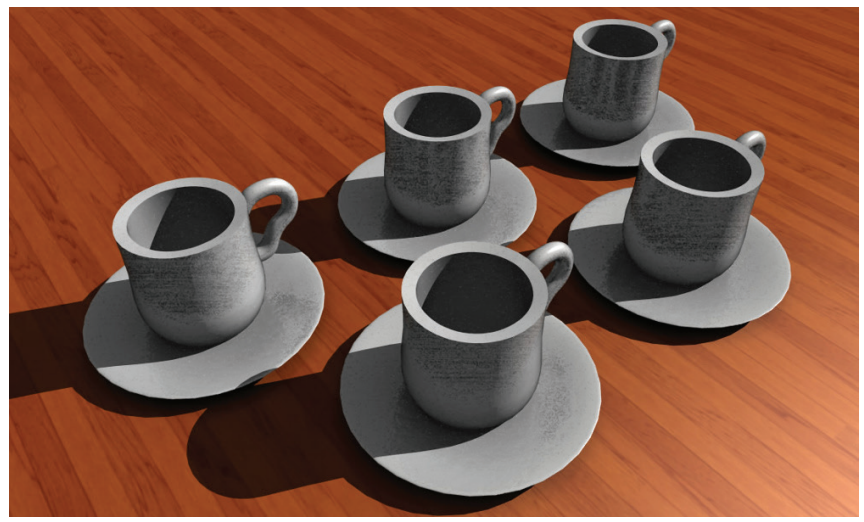

Figura 1: Artefatos idênticos. (Fonte: autores).

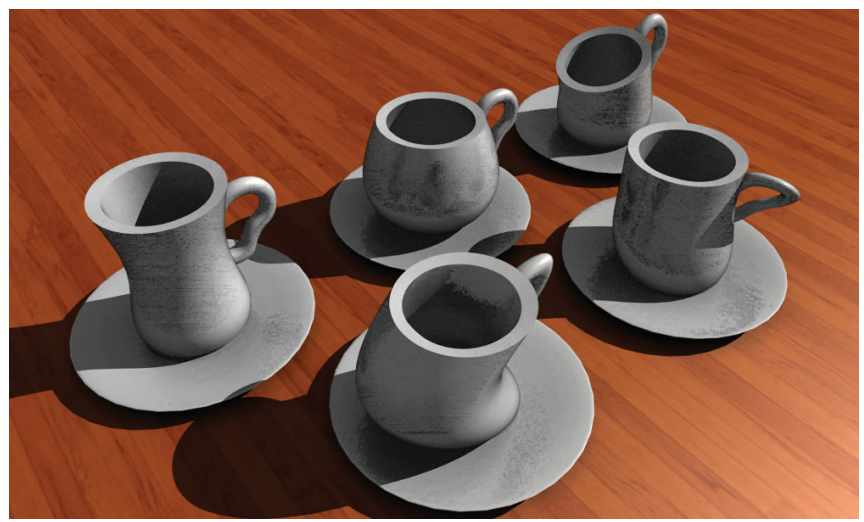

Figura 2: Artefatos customizados. (Fonte: autores).

É importante destacar que uma das turmas do ateliê de projeto do segundo semestre é a única experiência de ensino de customização em massa e que estimula a diversidade formal em andamento na escola pesquisada. Portanto, isto permitiu a constituição dos grupos pesquisados acima citados.
O questionário utilizado era composto de questões simples com resposta em múltipla escolha com a finalidade de ser compreendido de respondido de maneira rápida. O mesmo era dividido em três partes. As questões na primeira parte tinham por objetivo a identificação do perfil da pessoa entrevistada em termos de formação educacional, conhecimento e experiência. A segunda parte do questionário foi planejada com o propósito de verificar, por meios diferentes, se o respondente acreditava que a padronização em massa era a única maneira de produzir artefatos economicamente acessíveis ou se a customização em massa era uma alternativa viável. A terceira e última parte do questionário tinha por objetivo verificar até que ponto o respondente tinha uma boa compreensão de processos de produção em massa e detectar possíveis contradições. 0 questionário foi aplicado a um total de 36 pessoas.

A segunda linha de investigação se baseou na análise comparativa de duas amostras de trabalhos de alunos do segundo semestre de ateliê de projeto. Estes cursaram a disciplina na turma em que o conceito de customização em massa e os meios digitais de projetos vêm sendo introduzidos em níveis crescentes ao longo dos últimos sete anos e meio.

Esta disciplina de ateliê de projeto tem como tema específico as linguagens arquitetônicas, o que propiciou uma oportunidade de explorar a diversidade formal de soluções. Durante a maior parte do período estudado, o plano de curso previa a concepção de três projetos de pequeno porte: um edifício administrativo, um pequeno restaurante e um pequeno pavilhão de exposições.

O plano de curso desta turma de ateliê de projeto permaneceu relativamente estável durante sete anos e meio em questão, exceto por três modificações importantes a partir do terceiro ano do período estudado: em primeiro lugar, requisitos de formais ou de linguagem arquitetônica passam a integrar o programa de necessidades. Torna-se obrigatório então a adoção de linguagens distintas para cada um dos projetos: o primeiro deles deveria adotar uma linguagem modernista minimalista; o segundo uma linguagem desconstrutivista em que predominasse a composição de planos em ângulos distintos de 90 graus; o terceiro deles deveria adotar uma linguagem predominantemente curvilínea.

Em segundo lugar, são introduzidos, a partir do terceiro ano do período estudado, requisitos quanto à precedência dos meios de representação utilizados. Até então o uso simultâneo de meios tradicionais e digitais de representação era obrigatório. Contudo, era deixado a cargo do aluno escolher em que mídia iniciar a concepção de cada projeto. A partir do terceiro ano passou a ser obrigatória a utilização dos seguintes meios de representação, na seguinte ordem: o primeiro projeto seria concebido através do modelo físico manual e depois seria produzido o modelo virtual. No segundo projeto, dever-se-ia iniciar com o modelo virtual e depois produzir o modelo físico manualmente. No terceiro projeto, deverse-ia conceber o projeto inicialmente no modelo virtual e o modelo físico seria optativo. Uma pequena amostra destes últimos, escolhida entre os melhores trabalhos, passou a ser 
prototipada rapidamente.

Por fim, a terceira modificação introduzida a partir do terceiro ano do período estudado, consistiu na introdução do conceito de customização em massa de forma explícita, o que até então vinha sendo apenas mencionado de forma desestruturada.

Foi com base nestas três modificações, introduzidas no plano de curso a partir do terceiro ano, que foram definidas as duas amostras de trabalhos a serem analisados: a primeira delas compreendendo trabalhos do período anterior às modificações e a segunda incluindo trabalhos posteriores às mesmas.

Como um recorte de pesquisa e visando verificar a utilização de soluções customizadas curvilíneas, a amostra inclui trabalhos apenas do terceiro projeto, ou seja, de pequeno pavilhão de exposições.

Foi analisado um total de 138 trabalhos de acordo com quatro categorias: 1) predominantemente ortogonal ou planar; 2) predominância mista: curva simples e ortogonal; 3) predominantemente curva simples; 4) predominantemente dupla curvatura. As figuras 3, 4, 5 e 6 abaixo ilustram estas categorias.

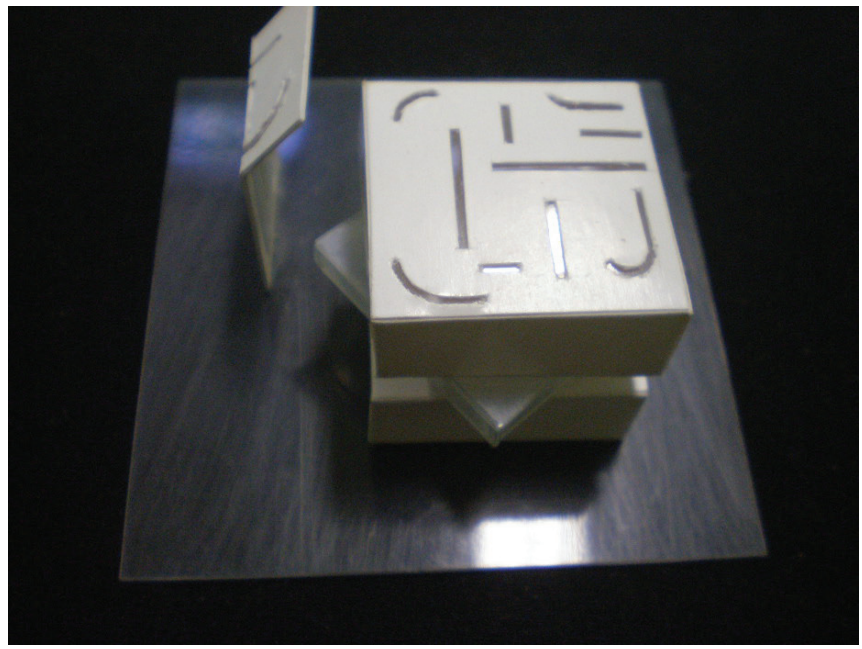

Figura 3: Predominantemente ortogonal (Fonte: autores).

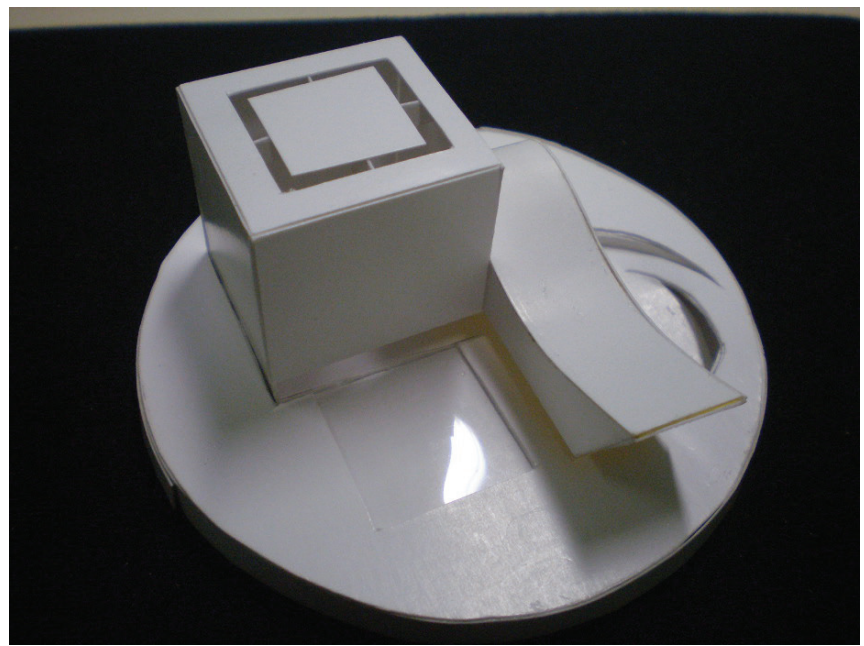

Figura 4: Mista: ortogonal e curva simples. (Fonte: autores).

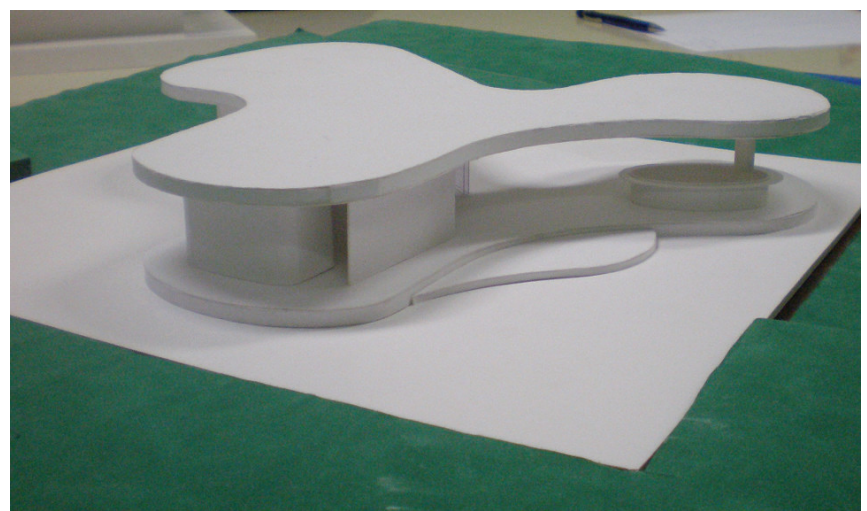

Figura 5: Predominantemente curva simples. (Fonte: autores).

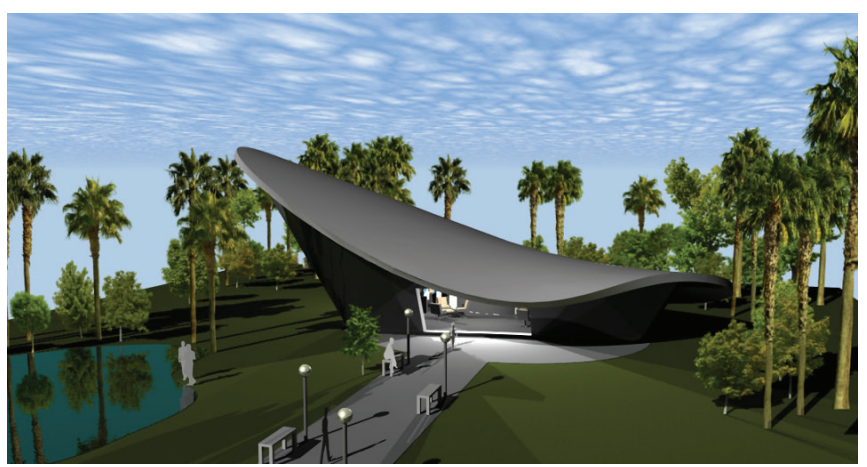

Figura 6: Predominantemente dupla curvatura. (Fonte: autores).

\section{Resultados}

O espaço nos permite relatar aqui parte dos dados obtidos. Os resultados globais da aplicação do questionário mostram que $72,2 \%$ dos respondentes acreditavam que o conjunto de artefatos customizados seria mais dispendioso de produzir do que os padronizados. Somente $16,7 \%$ dos respondentes acreditavam que o custo seria similar para ambos os conjuntos de artefatos. Apenas 2,8\% acreditava que o conjunto customizado seria menos dispendioso.

A quantidade de respondentes que acreditavam que os custos de produção seriam similares para ambos os conjuntos foi significativamente mais alta entre os alunos de pós-graduação (50\%) do que entre os de graduação (quase 0\%), mesmo entre aqueles que haviam sido introduzidos à customização em massa no segundo semestre do curso.

Entretanto, os resultados foram diferentes se os respondentes eram confrontados com a seguinte questão: "se alguém lhe dissesse que um conjunto de artefatos padronizados seria sempre mais barato que um conjunto de artefatos customizados, você concordaria?". Neste caso, dois terços dos alunos de pós-graduação escolheram como resposta o seguinte: "discordaria porque isto seria uma pressuposição inadequada para o presente estágio de desenvolvimento tecnológico".

Os resultados também mudaram quando os alunos de graduação foram confrontados com a seguinte questão: 
"se alguém lhe dissesse que um conjunto de artefatos customizados poderia ser produzido por um custo igual ou inferior ao dos padronizados, você concordaria?" Neste caso, $40 \%$ dos alunos do terceiro semestre que haviam sido anteriormente introduzidos à customização em massa disseram que concordariam, enquanto $60 \%$ dos mesmos disseram que considerariam necessário investigarem o assunto antes de se posicionarem. Entre os alunos do mesmo semestre, mas que não haviam sido introduzidos à customização em massa anteriormente, apenas 20\% disseram que concordariam, enquanto $70 \%$ dos mesmos disseram que considerariam necessário investigarem o assunto antes de se posicionarem.

No que diz respeito à análise comparativa de duas amostras de trabalhos de alunos do segundo semestre de ateliê de projeto que cursaram a turma onde a customização em massa e o estímulo a variabilidade foram introduzidos, o gráfico abaixo (Figura 7) apresenta a variação na ocorrência das quatro categorias descritas anteriormente.

Pode-se observar um grande decréscimo no número inicial de soluções predominantemente ortogonais e um aumento bastante significativo de soluções onde duplas curvaturas são predominantes. Os gráficos abaixo, exibindo o percentual total de ocorrências por período e por categoria, (Figuras 8 e 9) reforçam a tendência observada no gráfico da Figura 7.

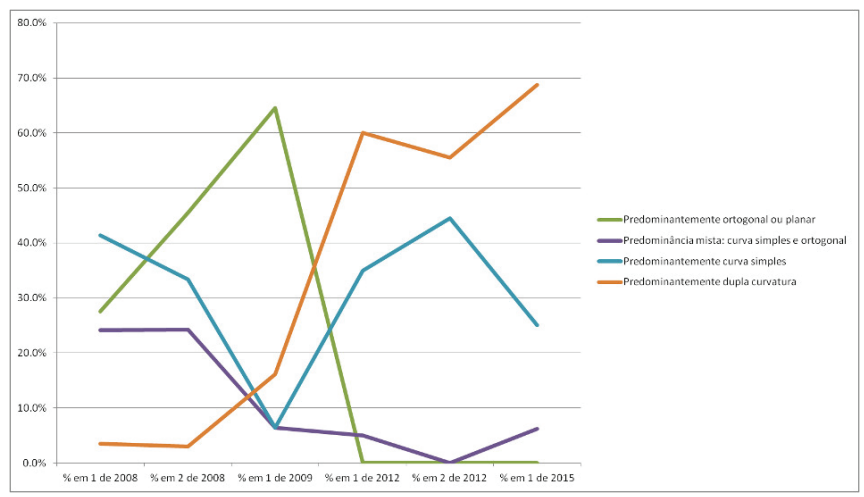

Figura 7: Predominância por categoria somenteem \% anual.(Fonte: autores).

Predominância formal em \% no $1^{\circ}$ Período

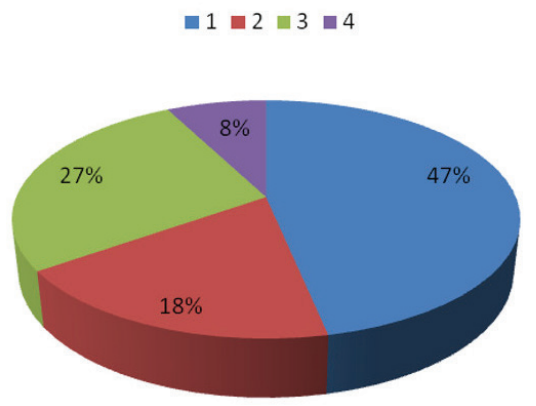

Figura 8: Predominância por categoria em \% no primeiro período analisado, onde: 1) Ortogonal, 2) Misto, 3) Curva simples, 4) Dupla curvatura. (Fonte: autores).

\section{Predominância formal em \% no $2^{\circ}$ Período}

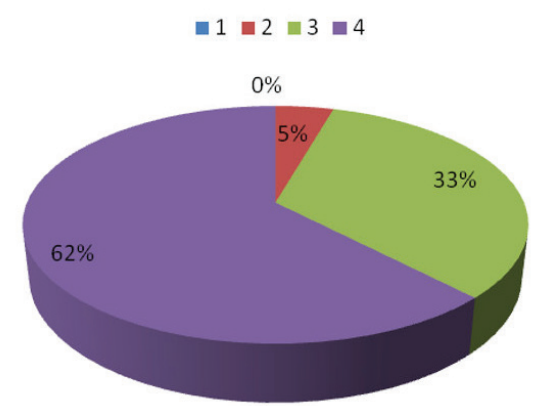

Figura 9: Predominância por categoria em \% no primeiro período analisado, onde: 1) Ortogonal, 2) Misto, 3) Curva simples, 4) Dupla curvatura. (Fonte: autores).

\section{Discussão}

Os resultados obtidos através da aplicação do questionário não foram exatamente conclusivos. Embora o percentual de alunos introduzidos à customização em massa que afirmaram que concordariam "se alguém lhe dissesse que um conjunto de artefatos customizados poderia ser produzido por um custo igual ou inferior ao dos padronizados" tenha sido o dobro (40\%) daqueles que não foram expostos ao conceito (20\%), o percentual de dúvida foi significativamente alto (60\%). Estes indicadores sugerem certa relevância ao método utilizado na introdução da customização em massa, ou seja, predominantemente teórico e ilustrativo. Contudo, ao mesmo tempo sugere ineficiência que precisa ser investigada.

\section{Conclusões}

Contudo, pudemos verificar que a simples informação e apresentação de exemplos de que a customização em massa é viável, por mais variada e exaustiva que seja, não é suficiente para a que os alunos a compreendam com tal.

Para superarmos esta ineficiência, acreditamos que é necessário uma extensa introdução prática à fabricação digital (corte 2D, subtração e adição) em nível de simulação dentro de sala de aula (o que não tem ocorrido até agora) e de alguma interação com a indústria local para que os alunos possam desenvolver alguma confiança de que a customização em massa é realmente viável.

A introdução e uso intensivo de técnicas de prototipagem rápida (corte CNC 2D, subtração e adição) em ateliê de projeto, como simulação de processos de fabricação digital na indústria, precisa ser considerada como pesquisa futura. É isto que estamos fazendo agora.

Por outro lado, os resultados da análise comparativa nos foram surpreendentes. Os alunos vêm produzindo formas não ortogonais e customizadas com uma frequência muito superior em consequência da introdução de condicionantes formais como requisito de projeto e da exigência de se conceber os projetos através de representações tridimensionais digitais. 


\section{Referências}

Barros, M., Duarte, J. P., E Chaparro, B., (2011) Thonet Chair Design Grammar : A Step towards the Mass Customization of Furniture, in: CAAD Futures 2011: Designing Together, p. 181200.

Benros, D., Granadeiro, V., Duarte, J., E Knight, T., (2011) Automated Design and Delivery of Relief Housing : The Case of post-Earthquake Haiti, in: CAAD Futures 2011: Designing Together, p. 247-264.

Franken, Bernhard, (2003) Real as Data, in: Branko Kolarevic, Architecture in the Digital Age - Design and Manufacturing, Taylor \& Francis, New York, p. 123-138.

Kieran, Stephen E Timberlake, James, (2004) Refabricating Architecture, McGraw-Hill, New York.

Kolarevic, B., (2003) Architecture in the Digital Age - Design and Manufacturing, Taylor \& Francis, New York.

Kolarevic, B. E Klinger, K., (2008) Manufacturing Material Effects: Rethinking Design and Making in Architecture, Taylor $\&$ Francis, New York.

Menges, A., (2008) Integral Formation and Materialization:
Computational Form and Material Gestalt, in: KOLAREVIC, B. e KLINGER, K., (Editores) Manufacturing Material Effects: Rethinking Design and Making in Architecture, Taylor \& Francis, New York.

Mitchell, William J., A Lógica da Arquitetura - Projeto, Computação e Cognição, Editora da Unicamp, Campinas, 2008. Moussavi, Farshid, (2009) The Function of Form, Harvard University Graduate School of Design \& Actar, New York.

Niemeyer, Oscar, (2005) A Forma na Arquitetura, Editora Revan, Rio de Janeiro, 4a Edição.

Polette, Doug E Landers, Jack M., (1995) Construction Systems, Goodheart-Willcox Company, Inc, Publishers, Illinois.

Schodek, D., Bechthold, M., Griggs, K., Kao, K. M. \& Steinberg, M. (2005) Digital Design and Manufacturing - CAD/CAM Applications in Architecture and Design, John Wiley \& Sons, New Jersey.

Sullivan, Louis. (2009) The Tall Office Building Artistically Considered, in Lippincott's Magazine (March 1896), citado por Higgins, Hannah B. The Grid Book, Cambridge, Massachusetts: MIT Press, p. 211. 